\section{Collaborative work brings hope for threatened harlequin toads}

Distributed in 11 countries in Central and South America, from tropical and montane forests to paramos, harlequin toads Atelopus spp. are highly threatened. According to the IUCN Red List, $83 \%$ of Atelopus species are threatened with extinction, with $40 \%$ possibly extinct in the wild and four species already extinct. Most Atelopus species have very small populations within severely reduced ranges, often in montane ecosystems, which makes them particularly susceptible to a myriad of threats, including infectious diseases, habitat loss and degradation, invasive species, illegal collection and climate change.

Individuals and organizations from several countries have recently joined forces to establish the Atelopus Survival Initiative, a collaborative and coordinated effort that unites and mobilizes a wide range of national and international stakeholders to implement substantial, long-term and comprehensive conservation measures to prevent the extinction of Atelopus.

In November 2019, 38 specialists from 11 countries, including seven where Atelopus species occur, convened in Medellin, Colombia, to identify and prioritize key strategic actions to ensure the survival of harlequin toads. As a result of this meeting and following 2 years of work, the Initiative was launched on 25 August 2021, together with the publication of the Harlequin Toad (Atelopus) Conservation Action Plan. Guided by the scientific expertise of the IUCN Species Survival Commission (Amphibian and Conservation Planning Specialist Groups, and Atelopus Task Force) and following the IUCN One Plan Approach, the Action Plan is envisioned as a cost-effective, simple, and dynamic plan to be implemented locally, taking into account the social, political and cultural realities of each country.

The Action Plan proposes the joint development of management and conservation actions agreed, conducted and implemented by all responsible parties, within or beyond the natural range of Atelopus. It outlines regional conservation priorities and identifies needs at local, national, regional and international levels that must be implemented over the next 20 years to achieve a shared vision by 2041 , the 200 th anniversary of the description of the genus.

The Action Plan promotes strategies to synchronize efforts and exchange resources, knowledge, and capacities among stakeholders through regional coordination and inter- and multidisciplinary approaches to: (1) produce baseline knowledge, (2) ensure viable populations in natural habitats, (3) maintain and manage captive populations for future reintroduction, (4) increase awareness of Atelopus, and (5) foster multi-stakeholder collaboration and participation. By incorporating a monitoring and evaluation framework, the Harlequin Toad (Atelopus) Conservation Action Plan will advance priorities and strategies for Atelopus conservation, updating objectives and actions as threats and conservation successes evolve.
LINA M. VALENCIA (ㅇ) orcid.org/000-0001-5513-563X, lvalencia@rewild.org) Re:wild, Austin, USA, and IUCN Species Survival Commission Atelopus Task Force. LuIS F. MARIN DA FONTE (10 orcid.org/0000-0001-8648-3178) Amphibian Survival Alliance, and IUCN Species Survival Commission Amphibian Specialist Group for Brazil and Atelopus Task Force

This is an Open Access article, distributed under the terms of the Creative Commons Attribution licence CC BY 4.0

\section{Quercus sichourensis and Pinus squamata fruit for the first time in ex situ cultivation}

In July and August 2021, Quercus sichourensis (Fagaceae) and Pinus squamata (Pinaceae), respectively, planted at Kunming Botanical Garden in Yunnan province, south-west China, were found to be bearing fruits. This is the first time the two species have been recorded to fruit in the Botanical Garden since they were propagated from seeds collected from wild populations in south-east Yunnan 12 and 9 years ago.

Both species are evergreen trees with high ornamental value. The leaves of $Q$. sichourensis are thick, leathery, whitish and pilose abaxially, and the nuts are large, each with one cupule enclosing nearly all of the nut, an arrangement different from most species in the genus Quercus. The unique characteristics of $P$. squamata are a straight trunk with white bark, branches sweeping downwards, and five needles per bundle.

With only 17 and 34 fully grown trees known to remain in the wild, respectively, and restricted areas of occupancy, $Q$. sichourensis and P. squamata are categorized as Critically Endangered on the IUCN Red List and both are listed in China as Plant Species with Extremely Small Populations. Pinus squamata also has grade I priority protection in China's National Key Protected Wild Plants. With these various categorizations and being at risk of extinction, these two species have attracted much attention. The fruiting of the species in Kunming Botanical Garden was

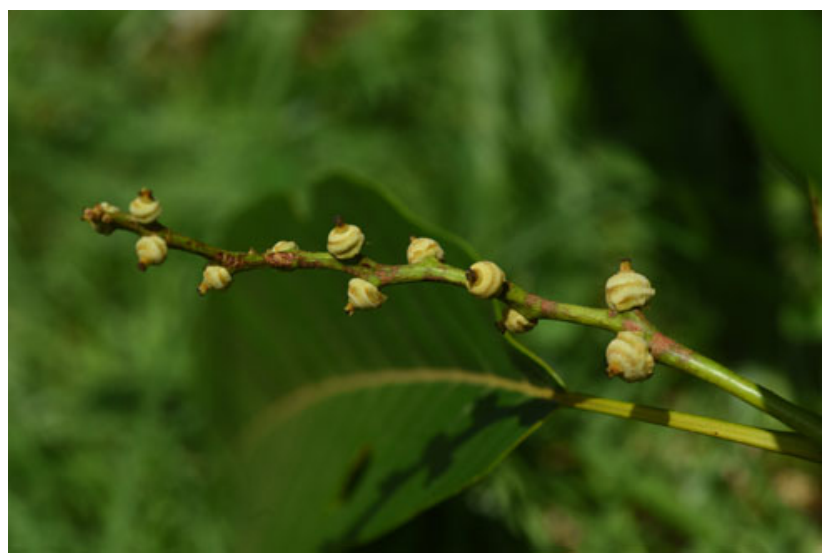

The unusual fruits of Quercus sichourensis, with the cupule enclosing nearly all of the nut. Photo: Zhifa Chen. 
reported by China's mainstream media and more than 2 million people viewed the news online.

With the support of several conservation projects, research has examined the threats to these two species, and conservation measures have been implemented. The wild populations of both species are protected by national natural reserves and micro-conservation sites established by local government departments. Thousands of seedlings have been propagated, some of which have been used for reinforcement and reintroduction in natural and seminatural sites within the species' known range, and others are being cultivated in various botanical gardens.

LIDAN TAO (@ orcid.org/0000-0002-1396-0524,wbsun@mail. kib.ac.cn) and WEIBANG SUN Yunnan Key Laboratory for Integrative Conservation of Plant Species with Extremely Small Populations, Kunming Institute of Botany, Chinese Academy of Sciences, Kunming, Yunnan, China. ZHIFA CHEN Kunming Botanical Garden, Kunming Institute of Botany, Chinese Academy of Sciences, Kunming, Yunnan, China

This is an Open Access article, distributed under the terms of the Creative Commons Attribution licence CC BY NC 4.0.

\section{An integrative approach for fungal conservation in southern Brazil}

Tropical cloud forests are characterized by occurring at mid to high elevations, and having high relative humidity, frequent presence of clouds, high biodiversity and a high per cent of endemic species. As a result of the intrinsic characteristics of this ecosystem, many of its species, in particular endemics, are highly threatened.

Since 2011, to mitigate the perilous combination of a threatened habitat and lack of knowledge about the fungi of the cloud forests of southern Brazil, the MIND.Funga initiative (mindfunga.ufsc.br) has been carrying out taxonomic and biodiversity studies and Red List assessments, as well as promoting citizen science and environmental education. More than 2,000 specimens of macrofungi, representing over 700 species, have been studied, new species described and an environmental education book for children published (mindfunga. ufsc.br/nossos-projetos/sbpc-vai-a-escola/?lang=en). Up to August 2021 the book had been downloaded c. 3,200 times.

On 25 March 2021, conservation assessments of three additional species were published on the IUCN Red List: Skeletocutis roseola and Stropharia venusta are categorized as Vulnerable and Wrightoporia araucariae as Critically Endangered. These are among the first Brazilian fungal species to be included on the Red List. So far, 46 species occurring in Brazil have been assessed.

Since March 2021, to improve knowledge of fungi in Brazil and to provide a new tool for conservation, we have been developing a citizen science programme. As part of this, a mobile application has been developed. We have so far trained 30

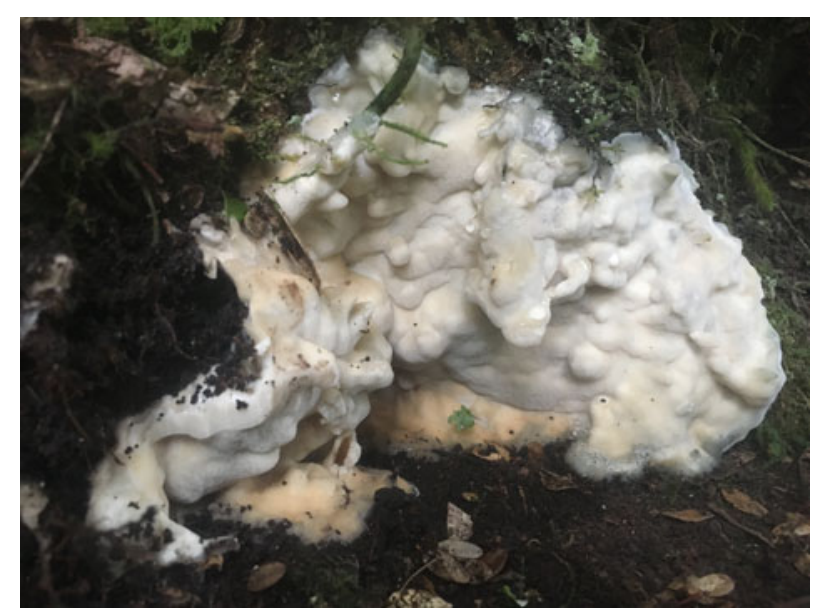

The Vulnerable Laetiporus squalidus (iucnredlist.org/species/ 187000831/187004590), a rare brown-rot polypore known only from the cloud forests and other montane ecosystems of the Serra do Mar. Photo: Cauê Azevedo Tomas de Oliveira.

collaborating citizens in using the application, and they have already registered 802 images of fungi, representing 206 specimens from cloud forests and adjacent areas, amongst which we have so far identified 74 species. The species most commonly found is Schizophyllum commune and none of the species known to be threatened have so far been recorded in this way. As a research group we believe that contributing to improved knowledge of the fungi of cloud forests in association with nonscientists, including children, will improve both fungal conservation and the conservation of the cloud forests of southern Brazil.

These MIND.Funga initiatives are supported by Fundação de Amparo à Pesquisa e Inovação de Santa Catarina (PRONEM2020TR733) and Conselho Nacional de Desenvolvimento Científico e Tecnológico (PQ311158/2018-8).

Diogo H. Costa-REZENDE (10 orcid.org/0000-0002-7381-6954) Laboratório de Pesquisa em Microbiologia, Departamento de Biologia, Universidade Estadual de Feira de Santana, Feira de Santana, Bahia, Brazil. Thiago Kossmann (잉 orcid.org/00000003-2858-7838), MAHATMÃ TitTON (10 orcid.org/0000-00017139-5116) and ELISANDRO RICARDO DRECHSLER-SANTOS* (ㅇ orcid. org/0000-0002-3702-8715,drechslersantos@yahoo.com.br) Laboratório de Micologia, Departamento de Botânica, Universidade Federal de Santa Catarina, Campus Universitário Trindade, Florianópolis, Santa Catarina, Brazil

${ }^{*}$ Also at: IUCN Species Survival Commission Mushroom, Bracket, and Puffball Specialist Group

This is an Open Access article, distributed under the terms of the Creative Commons Attribution licence CC BY 4.0.

\section{New toolkit to support teachers to teach about Philippine biodiversity}

A group of biodiversity researchers and conservation practitioners in the Philippines has teamed up with the country's 